\title{
Efektivitas Pendidikan Kesehatan Melalui Media Kartu Cinta Anak Tentang 1000 Hari Pertama Kehidupan dalam Meningkatkan Pengetahuan Pasangan Calon Pengantin di KUA Kecamatan Jatinangor
}

\author{
Dian Nurlaela ${ }^{1}$, Puspa Sari ${ }^{2}$, Neneng Martini ${ }^{3}$, Merry Wijaya ${ }^{4}$, R. Tina Dewi \\ Judistiani $^{5}$ \\ Program Studi Kebidanan Fakultas Kedokteran Universitas Padjadjaran ${ }^{1}$ \\ Departemen Ilmu Kesehatan Masyarakat Fakultas Kedokteran Universitas Padjadjaran 2,2,3,4,5 \\ diannurlaela33@yahoo.com ${ }^{1}$, saripuspabidan2@gmail.com ${ }^{2}$, neneng_martini@yahoo.co.id ${ }^{3}$, \\ merry_wijaya0605@yahoo.com ${ }^{4}$, judistiani@gmail.com ${ }^{5}$
}

\begin{abstract}
ABSTRAK
Latar Belakang: Periode Seribu Hari Pertama Kehidupan (Golden Periode) merupakan periode yang sangat kritis dimulai dari sejak saat konsepsi sampai anak usia 2 tahun yang jika tidak dimanfaatkan dengan baik akan terjadi kerusakan yang bersifat permanen seperti gangguan pertumbuhan fisik, kecerdasan, dan munculnya penyakit tidak menular. Calon pengantin merupakan salah satu kelompok sasaran untuk meningkatkan kualitas kesehatan pada 1000 Hari Pertama Kehidupan (1000 HPK). Peningkatkan kualitas kesehatan dapat dilakukan dengan pemberian pendidikan kesehatan melalui media Kartu Cinta Anak (KCA).

Tujuan: Untuk mengetahui efektivitas pendidikan kesehatan melalui media KCA tentang 1000 HPK dalam meningkatkan pengetahuan calon pengantin di KUA Kecamatan Jatinangor.

Metode Penelitian: Kuantitatif dengan design pre-eksperimental dalam bentuk pretest-posttest dilakukan pada bulan Juli 2017. Sampel penelitiannya adalah calon pengantin (catin) yang terdaftar di KUA Kecamatan Jatinangor merupakan pernikahan pertama dan belum mempunyai anak. Teknik pengambilan sampel dengan total sampling jumlah sampel 34 pasang responden. Analisis data menggunakan Uji Paired Sample t-test.

Hasil: Penelitian menunjukan bahwa penggunaan media KCA efektif dalam meningkatkan pengetahuan catin tentang $1000 \mathrm{HPK}$, hasil Uji Paired Sample t-test dengan nilai $<0,05(\mathrm{P}=0,000)$ yang artinya terdapat perbedaan yang signifikan terhadap peningkatan pengetahuan catin sebelum dan sesudah diberikan pendidikan kesehatan.

Kesimpulan: Penelitian ini adalah penggunaan media KCA efektif dalam meningkatkan pengetahuan catin tentang 1000 Hari Pertama Kehidupan.

Kata Kunci: Media Kartu Cinta Anak (KCA), Pendidikan Kesehatan, Pengetahuan calon pengantin, 1000 Hari Pertama Kehidupan.
\end{abstract}

\begin{abstract}
ABSTRACK
Background: The First Thousand Days of Life (Golden Period) is a very critical period from the moment of conception to infant aged 2-year-olds which, if not properly utilized, will have permanent damage such as impaired physical growth, intelligence, and non-communicable diseases. The soon-to-be married couple is one of the target groups to improve health quality in the First 1000 Days of Life (1000 FDL). Improvement of the quality of health can be achieved by providing health education using Kartu Cinta Anak (KCA).

Objective: The purpose of this study is to determine the effectiveness of health education using KCA about 1000 FDL in improving the knowledge of soon-to-be married couple in KUA Jatinangor Sub District.
\end{abstract}

Methods: This research used a quantitative method with pre-experimental design in the form of pretest-posttest, conducted in July 2017. The sample of the research are soon-to-be married couples registered in KUA Jatinangor sub district who have never been married and have not had children. The total number of samples are 34 pairs of respondents. Data analysis using Paired Sample t-test.

Results: The results showed that the use of KCA was effective in improving soon to be married couple's knowledge about $1000 \mathrm{FDL}$, with Paired Sample t-test value of $\angle 0,05(P=0,000)$, suggesting that there was significant difference in soon-to-be married couple's knowledge before and after health education. Conslusion: The conclusion of this research is the use of KCA is effective in improving the knowledge of soon-to-be married couple about the First 1000 Days of Life.

Keywords: Media Kartu Cinta Anak (KCA), Health Education, Knowledge of the bride and groom, First 1000 Days of Life. 


\section{PENDAHULUAN}

Seribu Hari Pertama Kehidupan atau yang dikenal dengan $1000 \mathrm{HPK}$ adalah fase kehidupan yang sangat penting, dimulai dari terbentuknya janin dalam kandungan sampai anak berusia 2 tahun. Periode ini disebut juga dengan periode emas (golden periode), yang jika tidak dimanfaatkan dengan baik akan terjadi kerusakan yang bersifat permanen (window of opportunity). (Gerakan Nasional Sadar Gizi, 2013). Pertumbuhan dan perkembangan otak pada periode ini terjadi sangat pesat yang harus didukung dengan kecukupan kebutuhan gizi. (UNICEF, 2014). (Woods, 2017).

Status gizi erat hubungannya dengan pertumbuhan dan perkembangan yang sangat pesat saat golden periode. Sedangkan masalah gizi merupakan salah satu masalah kesehatan tertinggi di dunia, terutama di Negara-negara berkembang. Sedangkan upaya untuk meningkatkan status gizi dalam rangka membangun sumber daya manusia yang berkualitas seharusnya dimulai sedini mungkin, yaitu sejak awal kehidupan janin dalam kandungan. ( Nasional Pedoman 1000 HPK, 2012).

Kegagalan pertumbuhan pada fase golden age ini dapat mengakibatkan gangguan pertumbuhan fisik seperti Stunting, Wasting, Berat Badan Lahir Rendah (BBLR), terganggunya perkembangan otak, kecerdasan, juga akan menyebabkan gangguan metabolik yang dapat memicu munculnya penyakit tidak menular seperti stroke, obesitas, diabetes, disabilitas, dan penyakit jantung koroner. Serta dampak dalam jangka panjang yang terjadi adalah menurunnya kemampuan kognitif, prestasi belajar, serta penurunan kekebalan tubuh sehingga mudah terkena penyakit. Penanganan masalah gizi pada 1000 Hari Pertama Kehidupan fokus dilakukan pada penurunan proporsi balita pendek (stunted), balita kurus (wasted), anak yang lahir dengan berat badan rendah dan gizi lebih / obesitas pada anak, serta meningkatkan presentase ASI ekslusif dan menurunkan proporsi anemia pada wanita usia subur. (BAPPENAS, 2012).

Masalah gizi di Kabupaten Sumedang, secara tidak langsung berdampak pada kematian bayi. Pada tahun 2013 angka kematian bayi mencapai 205 dari 282 pada tahun 2012, pada angka kematian balita mengalami kenaikan dari 28 balita menjadi menjadi 46 balita. Puskesmas yang paling banyak melaporkan kematian bayi dan balita salah satunya adalah puskesmas Jatinangor. Kematian bayi sebanyak 16 orang, kematian balita sebanyak 3 orang. Di puskesmas Jatinangor, balita yang memiliki gizi lebih sebanyak 2,57\%, gizi kurang sebanyak $6,69 \%$, dan mengalami gizi buruk sebayak 0,38\%. (Profil Daerah Sumedang, 2014).

Konsumsi gizi yang tidak sesuai dengan aturan dapat menyebabkan masalah kesehatan. (Sandjaja, 2013). Kelompok sasaran untuk meningkatkan kualitas kesehatan pada 1000 Hari Pertama Kehidupan dimulai dari wanita usia subur, pasangan calon pengantin, ibu hamil, ibu menyusui, bayi baru lahir dan anak usia di bawah dua tahun (baduta). Kelompok sasaran ini merupakan kelompok yang rentan terhadap gizi. (Hariyani, 2011).

Peneliti dalam hal ini memilih Pasangan calon pengantin atau pasangan yang akan menikah menjadi kelompok sasaran dalam penelitian. Calon pengantin (Catin) merupakan WUS yang akan menikah, yang dipersiapkan agar mempunyai kondisi sehat sebelum hamil supaya dapat melahirkan bayi yang sehat. (Pusdatin, 2017). Hasil penelitian menurut Luz M De-Regil, dkk menyebutkan bahwa pemberian pengetahuan mengenai gizi sebelum hamil sangatlah penting pada kelompok wanita pra-hamil termasuk calon pengantin wanita yang nantinya akan mempersiapan kehamilannya. (Luz, 2016). Penelitian lain yang dilakukan oleh Yuli Trisnawati, dkk di Kabupaten Banyumas menyebutkan bahwa sebagian besar tingkat pengetahuan yang dijadikan responden dalam penelitian tentang gizi 1000 Hari Pertama Kehidupan adalah kurang. (Trisnawati, 2016). Sedangkan menurut penelitian yang dilakukan oleh Husna tahun 2017 nutrisi pada 1000 hari pertama kehidupan dapat memperbaiki kualitas sumber daya manusia di masa depan. (Husna, 2017)

Salah satu cara yang dapat digunakan untuk meningkatkan pengetahuan tentang 
pemenuhan gizi seimbang khususnya pada periode 1000 Hari Pertama Kehidupan pada pasangan calon pengantin adalah dengan memberikan pendidikan kesehatan, agar pemberian pendidikan kesehatan lebih efektif maka digunakan media yang menarik. (Fitriani, 2011). Salah satu media untuk memberikan pendidikan kesehatan yaitu menggunakan kartu. Peneliti membuat sebuah kartu yang disebut kartu cinta anak (KCA), karena berdasarkan penelitian Shafira Evi menyebutkan bahwa penggunaan media promosi kesehatan kartu kwartet lebih efektif dibandingkan media slide. (Evi, 2013). Penelitian lain yang dilakukan oleh Masije Marlyn Kuhu, dkk juga menyebutkan bahwa penggunaan Flashcards lebih efektif dibandingkan dengan Word Cards. (Masije, 2011).

Berdasarkan masalah-masalah yang telah dijelaskan, peneliti menggunakan pendidikan kesehatan melalui media kartu cinta anak (KCA) sebagai upaya intervensi kepada masyarakat terutama pasangan calon pengantin guna meningkatkan pengetahuan tentang gizi seimbang pada 1000 Hari Pertama Kehidupan.

\section{METODE}

Metode penelitian ini menggunakan jenis penelitian pre-experimental design dalam bentuk pretest-posttest design. Peneliti membandingkan peningkatan pengetahuan calon pengantin sebelum dan setelah diberikan pendidikan kesehatan menggunakan Kartu Cinta Anak (KCA) tentang 1000 Hari Pertama Kehidupan. Penelitian ini dilaksanakan bulan Juli 2017. Populasi pada penelitian ini adalah seluruh pasangan calon pengantin yang terdaftar di KUA Kecamatan Jatinangor pada bulan Juli 2017 yang berjumlah 46 pasangan, dan yang termasuk kriteria inklusi yaitu sebanyak 34 pasangan.

Kriteria inklusi adalah pasangan calon pengantin yang menikah pertama, belum mempunyai anak, calon pengantin wanita beralamatkan di Jatinangor, dan bersedia untuk dijadikan sampel penelitian. Sedangkan kriteria eksklusi adalah pasangan calon pengantin tidak hadir saat proses pengambilan data dan yang tidak menyetujui untuk dijadikan sampel penelitian. Analisis data pada penelitian ini merupakan analisis univariat untuk mengetahui gambaran pengetahuan pre-test dan post-test berupa tabel frekuensi serta analisis bivariat dengan Uji Paired Sample t-test untuk melihat efektivitas media Kartu Cinta Anak (KCA) dalam meningkatkan pengetahuan pasangan calon pengantin tentang 1000 Hari Pertama Kehidupan. Kemaknaan hasil uji ditentukan berdasarkan nilai $\mathrm{p}<0,05$. Penelitian ini telah mendapatkan persetujuan dari Komite Etik Penelitian Kesehatan Universitas Padjadjaran Fakultas Kedokteran no: 599/UN6.C.10/PN/2017.

HASIL DAN PEMBAHASAN

Tabel 1. Gambaran Pengetahuan Pasangan Calon Pengantin mengenai 1000 Hari Pertama Kehidupan Sebelum dan Sesudah Diberikan Pendidikan Kesehatan Melalui Kartu Cinta Anak (KCA) di KUA Kecamatan Jatinangor Tahun 2017

\begin{tabular}{ccccccccc}
\hline $\begin{array}{c}\text { Pengetahuan } \\
\text { tentang 1000 } \\
\text { HPK }\end{array}$ & \multicolumn{4}{c}{ Sebelum } & \multicolumn{5}{c}{ Sesudah } \\
\cline { 2 - 10 } & \multicolumn{3}{c}{$\mathrm{L}$} & \multicolumn{2}{c}{$\mathrm{P}$} & \multicolumn{2}{c}{$\mathrm{L}$} & $\mathrm{P}$ \\
\cline { 2 - 10 } & $(\mathrm{n})$ & $(\%)$ & $(\mathrm{n})$ & $(\%)$ & $(\mathrm{n})$ & $(\%)$ & $(\mathrm{n})$ & $(\%)$ \\
Baik & 1 & 2,9 & 5 & 14,7 & 15 & 44,1 & 18 & 52,9 \\
Cukup & 18 & 52,9 & 17 & 50,0 & 17 & 50,1 & 15 & 44,1 \\
Kurang & 15 & 44,1 & 12 & 35,3 & 2 & 5,9 & 1 & 2,9 \\
Total & 34 & 100 & 34 & 100 & 34 & 100 & 34 & 100 \\
& & & & & & & &
\end{tabular}

Berdasarkan tabel 1, didapatkan hasil bahwa calon pengantin laki-laki yang memiliki pengetahuan kurang sebelum diberikan pendidikan kesehatan sebanyak 15 orang $(44,1 \%)$, dan setelah diberikan pendidikan kesehatan jumlahnya menurun menjadi 2 orang $(5,9 \%)$. Sedangkan calon pengantin laki-laki yang memiliki pengetahuan baik setelah diberikan pendidikan kesehatan meningkat dari 1 orang (2,9\%) menjadi 15 orang $(44,1 \%)$.

Responden calon pengantin perempuan yang memiliki pengetahuan kurang sebelum diberikan pendidikan kesehatan sebanyak 12 orang (35,3\%), dan setelah diberikan pendidikan kesehatan jumlahnya menurun menjadi 1 orang (2,9\%). Sedangkan calon pengantin perempuan yang memiliki pengetahuan baik setelah diberikan pendidikan kesehatan meningkat dari 5 orang $(14,7 \%)$ menjadi 18 orang 
(52,9\%). Terjadi peningkatan pengetahuan calon pengantin laki-laki dan perempuan sebelum dan sesudah diberkan pendidikan kesehatan melalui Media Kartu Cinta Anak tentang 1000 Hari Pertama Kehidupan.

Berdasarkan tabel 1, didapatkan hasil bahwa sebelum diberikan pendidikan kesehatan yang memiliki pengetahuan kurang untuk calon pengantin laki-laki sebanyak $15(44,1 \%)$ orang dan calon pengantin perempuan sebanyak $12(35,3 \%)$ orang. Sedangkan yang memiliki pengetahuan baik sebelum diberikan pendidikan kesehatan untuk calon pengantin laki-laki sebanyak 1 orang $(2,9 \%)$ dan perempuan sebanyak 5 orang $(14,7 \%)$. Setelah diberikan pendidikan kesehatan yang memiliki pengetahuan kurang untuk calon pengantin laki-laki sebanyak $2(5,9 \%)$ orang dan calon pengantin perempuan sebanyak 1 (2,9\%) orang, sedangkan yang memiliki pengetahuan baik untuk calon pengantin laki-laki sebanyak 15 orang $(44,1 \%)$ dan perempuan sebanyak 18 orang $(52,9 \%)$. Terjadi peningkatan pengetahuan calon pengantin laki-laki dan perempuan sebelum dan sesudah diberkan pendidikan kesehatan melalui Media Kartu Cinta Anak tentang 1000 Hari Pertama Kehidupan.

Hasil penelitian menunjukan bahwa tingkat pengetahuan pasangan calon pengantin tentang 1000 Hari Pertama Kehidupan sebelum diberikan pendidikan kesehatan masih kurang. Hasil penelitian ini sejalan dengan penelitian yang dilakukan oleh Yuli Trisnawati, dkk tentang pengetahuan dan sikap ibu hamil tentang gizi 1000 Hari Pertama Kehidupan di Kabupaten Banyumas yang menyebutkan sebagian besar tingkat pengetahuan responden yang dijadikan sampel penelitian adalah kurang. (Trisnawati, 2016).

Pengetahuan merupakan salah satu kunci perubahan perilaku. Tingkat pengetahuan dipengaruhi oleh beberapa faktor, antara lain keterpaparan informasi kesehatan, umur, dan peran dari tenaga kesehatan dalam memberikan informasi kesehatan. Selain itu tingkat pendidikan juga berpengaruh terhadap tingkat pengetahuan, tingkat pendidikan merupakan faktor sosial yang memengaruhi bagaimana ia akan bersikap dan berperilaku. (Brug, 2015).

Apabila pengetahuan tentang 1000 Hari Pertama Kehidupan kurang, dampak yang akan timbul salah satunya adalah akan mengalami kekurangan gizi pada periode tersebut yang akan mengakibatkan gangguan pertumbuhan fisik seperti Stunting, Wasting, Berat Badan Lahir Rendah (BBLR), juga terganggunya perkembangan otak, kecerdasan, juga akan menyebabkan gangguan metabolik yang dapat meningkatkan resiko pada terjadinya penyakit tidak menular seperti stroke, obesitas, diabetes, disabilitas, dan penyakit jantung koroner. (WHO, 2009). Berdasarkan penelitian yang dilakukan Widya dkk di Malang tentang masalah gizi pada 1000 Hari Pertama Kehidupan, menyebutkan bahwa masih terdapat banyak masalah gizi seperti Stunting, Wasting, yang salah satu faktornya adalah ketidak tahuan ibu tentang bagaimana pemenuhan gizi pada periode 1000 Hari Pertama Kehidupan. (Rahmawati, 2016)

Menurut Notoatmodjo pengetahuan merupakan hasil dari tahu. Didapat seseorang dari hasil pengindraan terhadap sesuatu objek tertentu. Pengetahuan itu sangat penting yang dapat mempengaruhi perilaku seseorang. Perilaku yang didasari oleh pengetahuan akan lebih baik daripada yang tidak di dasari olrh pengetahuan. (Notoatmodjo, 2012).

Pengetahuan yang baik sangat penting karena diharapkan dengan pengetahuan yang baik akan membentuk sikap yang baik juga baik bagi calon ibu ataupun calon ayah nantinya terhadap pentingnya 1000 hari pertama kehidupan janinnya terutama masalah gizi pada periode tersebut. (Soekidjo, 2012)

Hasil penelitian ini juga menyebutkan tingkat pengetahuan calon pengantin laki-laki yang memiliki pengetahuan kurang lebih besar daripada calon pengantin perempuan, hal ini sejalan dengan hasil penelitian yang dilakukan oleh Agumelar di Bogor yang menyebutkan bahwa subjek perempuan memiliki pengetahuan gizi baik lebih tinggi dibandingkan subjek laki-laki, yang berarti pengetahuan gizi laki-laki sebagian besar masih kurang. (Agumelar, 2014). Selain itu, menurut Lin tahun 2012 pengetahuan gizi, 
sikap serta perilaku kecuali emosional dan perilaku eksternal pada perempuan lebih baik daripada laki-laki. Hal tersebut bisa juga dipengaruhi oleh beberapa faktor seperti keterpaparan infomasi kesehatan, dan peran dari tenaga kesehatan dalam memberikan infomasi kesehatan khususnya tentang 1000 Hari Pertama Kehidupan yang lebih memfokuskan ke kelompok sasarannya yaitu terhadap perempuan. (Agumelar, 2014)

Hal ini merupakan keadaan awal yang kurang baik walaupun nantinya perempuan yang akan mendominasi dalam mengurus anak dari mulai masa kehamilan, melahirkan menyusui, dan mendidik, namun bukan berarti promosi gizi atau pendidikan gizi tidak perlu diberikan kepada laki-laki sebagai calon suami dan calon ayah. Karena calon suami seharusnya ikut berperan penting dalam merencanakan kehidupan anak atau keturunannya. Sehingga diperlukan pengetahuan yang baik mengenai pentingnya 1000 Hari Pertama Kehdiupan agar dapat mencegah dampak yang dapat terjadi bila periode 1000 Hari Pertama Kehidupan ini pertumbuhan dan perkembangan anak tidak optimal terutama pada pemenuhan gizi seimbang.

Peran suami di Indonesia masih sangat penting dan kuat dalam mengambil keputusan termasuk keputusan yang terkait dengan kesehatan. Apabila laki-laki atau suami pernah mendapatkan materi gizi 1000 HPK sebelumnya, diharapkan dapat berperilaku yang postif seperti dukungan kepada istri dan anaknya dalam memperhatikan kondisi kesehatan maupun kebutuhan gizi khususnya pada periode 1000 Hari Pertama Kehidupan. Hal ini sejalan dengan hasil penelitian yang dilakukan oleh Ishak dkk tahun 2015 tentang keterlibatan suami dalam proses kehamilan maupun persalinan istri, menunjukan hasil bahwa semakin tinggi tingkat pendidikan suami maka semakin tinggi pula dukungan suami terhadap istrinya untuk memilih tempat persalinan dan berkonsultasi ke tenaga kesehatan, serta dukungan terhadap pemenuhan gizi selama kehamilan. (Koka, 2014).

Setelah diberikan pendidikan kesehatan, hasil penelitian menunjukan terjadi peningkatan pengetahuan pada pasangan calon pengantin tentang 1000 Hari Pertama Kehidupan menggunakan media Karu Cinta Anak (KCA).

Hasil penelitian ini sejalan dengan Penelitian lain yang dilakukan oleh Masije Marlyn Kuhu, dkk tentang The Effectiveness Of Flashcards and Word Cards In Improving Knowledge and Attitude Worms In The Elementary School Children menyebutkan bahwa penggunaan Flashcards lebih efektif dibandingkan dengan Word Card. Dalam penelitian ini media Kartu Cinta Anak (KCA) yang hampir sama dengan flashcards menunjukan peningkatan pengetahuan pada kedua pasangan calon pengantin. (Masije, 2011)

Menurut Notoatmojo (2012), melakukan pendidikan kesehatan dapat menghasilkan perubahan atau peningkatan pengetahuan dengan metode yang tepat. Terdapat berbagai metode dan media yang dapat digunakan dalam melakukan pendidikan kesehatan, seperti media elektronik (TV, Radio) media cetak seperti leaflet, spanduk, poster, koran, termasuk media kartu yang dapat disesuaikan dengan target dan jumlah sasaran yang akan dicapai. Dikarenakan dalam penelitian ini pengambilan data dilakukan dengan cara orang perorangan media kartu dapat dijadikan salah satu pilihan. (Machfoedz, 2009).

Dengan media Kartu Cinta Anak (KCA) yang digunakan dalam penelitian terjadi peningkatan pengetahuan pada kedua pasangan calon pengantin setelah dilakukan pendidikan kesehatan, namun

dari hasil penelitian masih ada yang berpengetahuan kurang, kemungkinan ini dapat terjadi karena saat dilakukan pendidikan kesehatan pasangan calon pengantin kurang fokus disebabkan pada saat pengambilan data ada yang dilakukan sebelum melakukan ijab qabul dengan kondisi diruangan yang ramai dengan keluarga, saksi, dan wali pernikahan. 
Tabel 2. Efektivitas Penggunaan Kartu Cinta Anak (KCA) dalam Meningkatkan

Pengetahuan Pasangan Calon Pengantin tetntang 1000 Hari Pertama Kehidupan di KUA Kecamatan Jatinangor Tahun 2017

\begin{tabular}{ccccccc}
\hline Pengetahuan & Min & Maks & Mean & SD & Mean & $\begin{array}{c}\text { Nilai } \\
\text { p }\end{array}$ \\
\hline $\begin{array}{c}\text { Laki-laki } \\
\text { (Pre-test) }\end{array}$ & 45 & 85 & 60,59 & 9,516 & 14,853 & 0,000 \\
$\begin{array}{c}\text { Laki-laki } \\
\text { (Post-test) }\end{array}$ & 55 & 95 & 75,44 & 10,615 & & \\
$\begin{array}{c}\text { Perempuan } \\
\text { (Pre-test) }\end{array}$ & 45 & 90 & 65,44 & 11,701 & 13,088 & 0,000 \\
$\begin{array}{c}\text { Perempuan } \\
\text { (Post-test) }\end{array}$ & 55 & 100 & 78,53 & 13,344 & & \\
\hline
\end{tabular}

Berdasarkan tabel 2, didapatkan hasil bahwa responden kedua pasangan calon pengantin laki-laki dan perempuan memiliki peningkatan nilai rata-rata pengetahuan setelah dilakukan pendidikan kesehatan yaitu sebesar 14,853 dan 13,088.

Hasil analisis bivariat menggunakan uji Paired Sample $t$-test didapatkan p value $=$ 0,000 pada calon pengantin laki-laki dan perempuan yang berarti $\mathrm{p}<0,05$ adalah terdapat perbedaan pengetahuan yang bermakna antara sebelum diberikan pendidikan kesehatan dengan sesudah diberikan pedidikan kesehatan.

Berdasarkan tabel 2, penggunaan media Kartu Cinta Anak efektif dalam meningkatkan pengetahuan pasangan calon pengantin tentang 1000 Hari Pertama Kehidupan karena dari hasil analisa data yang digunakan dengan menggunakan Uji Paired Sample t-test menunjukan peningkatan nilai rata-rata skor pengetahuan setelah dilakukan pendidikan kesehatan dan nilai $\mathrm{p}$ value $=0,000$ pada responden laki-laki dan perempuan. Karena $p<0,05$, sehingga dapat disimpulkan bahwa terdapat perbedaan pengetahuan yang signifikan antara sebelum dan sesudah diberikan pendidikan kesehatan.

Penelitian ini sejalan dengan penelitian yang dilakukan oleh Shafira Evi tentang Efektivitas Media Promosi Kartu Kwartet dengan Slide di Kecamatan Depok Sleman menyebutkan bahwa penggunaan media promosi kesehatan kartu kwartet lebih efektif dibandingkan media slide. Dikarenakan media kartu yang bergambar dan dibuat seperti sebuah permainan yang artinya responden diminta untuk berinteraksi sehingga menjadikan lebih mudah ingat. Seperti pada penggunaan KCA reponden diminta melakukan interaksi tanya jawab yang dipandu oleh peneliti. (Evi, 2013).

Menurut teori yang dikemukakan oleh Elgar Dale yang membagi 11 macam alat peraga dalam menggambarkan tingkat intensitas penerimaan pengetahuan dalam sebuah kerucut yang menempatkan discussion dan audio-visual lebih besar dengan hanya membaca dan mendengarkan saja. Sesuai teori Elgar Dale bahwa tampilan Kartu Cinta Anak (KCA) yang bergambar dan penggunaanya melalui metode diskusi ceramah mempengaruhi peningkatan pengetahuan pasangan calon pengantin. (Machfoedz, 2009).

Dengan kata lain penggunaan media Kartu Cinta Anak (KCA) sebagai media promosi kesehatan, efektif terhadap peningkatan pengetahuan tentang 1000 Hari Pertama Kehidupan (1000 HPK) pada pasangan calon pengantin (Catin) di KUA Kecamatan Jatinangor.

\section{PENUTUP}

\section{Simpulan}

Penggunaan media Kartu Cinta Anak (KCA) efektif dalam meningkatkan pengetahuan calon pengantin (catin) tentang 1000 Hari Pertama Kehidupan (1000 HPK) karena dilihat dari hasil analisis data didapatkan nilai $\mathrm{p}<0,05(\mathrm{p}=0,000)$ yang artinya terdapat perbedaan yang signifikan terhadap peningkatan pengetahuan catin sebelum dan sesudah diberikan pendidikan kesehatan. Media KCA ini dapat digunakan sebagai media pendidikan kesehatan untuk meningkatkan pengetahuan tenang 100 Hari Pertama Kehidupan. Saran untuk peneliti selanjutnya yaitu melakukan penelitian terhadap hasil luaran pada responden dalam penelitian ini yang telah mendapatkan pengetahuan mengenai 1000 Hari Pertama Kehidupan.

\section{UCAPAN TERIMA KASIH}

Ucapan terima kasih kepada KUA Kecamatan Jatinangor yang telah memberi izin untuk melakukan penelitian di lokasi kerja KUA Kecamatan Jatinangor dan 
pasangan calon pengantin yang bersedia untuk berpartisipasi dalam kegiatan penelitian ini.

\section{DAFTAR PUSTAKA}

Agumelar, T. (2014). Pengetahuan Gizi dan Pengetahuan tentang Masalah Gizi Stunting pada Siswa SMAN 3 Bogor. Bogor: Institut Pertanian Bogor.

BAPPENAS. (2012). Laporan Pencapaian Tujuan Pembangunan Milenium di Indonesia 2012. Jakarta: Kementerian Perencanaan Pembangunan Nasional.

BPP, N. (2012). Pedoman Perencanaan Program Gerakan Sadar Gizi Dalam Rangka Seribu Hari Pertama Kehidupan (1000 HPK). Jakarta: Badan Penelitian dan Pengembangan Nasional.

Brug J OA, Kroeze W, R. H. E. J. of C., \& Nutr. (2015). The Internet and Nutrition Education. In Challenges and Opportunities.

Evi, S. (2013). Efektivitas Media Promosi Kartu Kwartet dengan Slide terhadap Pengetahuan dan Sikap Siswa Sekolah Dasar tentang Perilaku Hidup Bersih Sehat di Kecamatan Depok Sleman Universitas Gajah Mada.

Fitriani. (2011). Promosi Kesehatan. Yogyakarta: Graha Ilmu.

Hariyani. (2011). Gizi untuk Kesehatan Ibu dan Anak. Yogyakarta: Graha Ilmu.

Husnah. (2017). Nutrisi pada 1000 Hari Pertama Kehidupan. Jurnal Kedokteran Syiah Kuala, 17, 179-183.

Kemenkes RI. (2012). Penuhi Kebutuhan Gizi pada 1000 Hari Pertama Kehidupan.

Kementerian Kesehatan Republik Indonesia. (2014). 1000 Hari Pertumbuhan yang Menentukan. Jakarta.

Koka, E. (2014). Pengaruh Pendidikan Gizi 1000 Hari Pertama Kehidupan terhadap Pengetahuan dan Sikap Siswa SMAN 1 Secanggang Kabupaten Langkat. Medan: Universitas Sumatera Utara.

Luz M De-Regil KBH, and M. L. R. (2016). Preconceptional Nutrition Interventions for Adolescent Girls and Adult Women. The Journal of Nutrition.

Machfoedz IdES. (2009). Pendidikan Kesehatan Bagian dari Promosi Kesehatan. Yogyakarta: Fitramaya.
Masije, M. K. D. (2011). The effectiveness Of Flashcards and Word Cards In Improving Knowledge and Attitude Worms In The Elementary School Children. Poltekkes Semarang.

Notoatmodjo, S. (2012). Promosi Keshatan dan Perilaku Kesehatan. Jakarta: Rineka Cipta.

Profil Daerah Kabupaten Sumedang. (2014).

Pusdatin. (2006). Glosarium. Retrieved from www.depkes.go.id/resources/downloa $\mathrm{d} /$ pusdatin/lain-lain/glosarium 2006.pdf

Rahmawati W, D. (2016). Gambaran Masalah Gizi pada 1000 HPK di Kota dan Kabupaten Malang. Indonesia Journal of Human Nutrition, Vol. 3(No. 1), 20-31.

Republik Indonesia. (2013). Kerangka Kebijakan Gerakan Nasional Sadar Gizi dalam Rangka 1000 Hari Pertama Kehidupan.

Sandjaja SB, B., Harahap, H., Ernawati, F. Soekatri, M., Widodo, Y. Sumedi, E., Rustan, E. Sofia, G. Syarief, SN., Khouw, I. (2013). Food consumption and nutritional and biochemical status of 0.5-12 year-old Indonesian children: the SEANUTS study. British Journal of Nutrition.

Soekidjo N. (2012). Promosi Kesehatan an perilaku kesehatan. Jakarta: PT Rineka Cipta.

Trisnawati, Y. (2016). Studi Deskriptif Pengetahuan dan Sikap Ibu Hamil Tentang Gizi 1000 Hari Pertama Kehidupan di Puskesmas Sokaraja Kabupaten Banyumas. Jurnal Kebidanan, VIII(No. 2).

UNICEF. (2014). Ringkasan Kajian Kesehatan Ibu dan Anak 2014. Retrieved from www.unicef.org

WHO. (2009). Second Report on the World Nutrition Situation. In Volume I: Global and Regional Result. Geneva: UN Standing Committe on Nutrition.

Woods, L. (n.d.). Seven Key Reasons why the first 1000 days are critical. Retrieved from

http:/ / www.everychildcounts.org.nz/r esources/seven-reasons/ 